\title{
UNIVERSITYOF
}

FORWARD

THINKING

WESTMINSTER用

WestminsterResearch

http://www.westminster.ac.uk/westminsterresearch

Identifying trends and flows in Communication and Information

Processing by means of keyword network analysis

Dotsika, F. and Watkins, A.

This is an electronic version of a paper presented at the 3rd International Conference on Communication and Information Processing, Tokyo, Japan, 24 to 26 November 2017.

(C) Dotsika, F. and Watkins, A. | ACM 2017. This is the author's version of the work. It is posted here for your personal use. Not for redistribution. The definitive Version of Record is published in the proceedings of the 3rd International Conference on Communication and Information Processing:

https://dx.doi.org/10.1145/3162957.3162990

The WestminsterResearch online digital archive at the University of Westminster aims to make the research output of the University available to a wider audience. Copyright and Moral Rights remain with the authors and/or copyright owners.

Whilst further distribution of specific materials from within this archive is forbidden, you may freely distribute the URL of WestminsterResearch: ((http://westminsterresearch.wmin.ac.uk/)).

In case of abuse or copyright appearing without permission e-mail repository@westminster.ac.uk 


\section{Identifying trends and flows in Communication and Information Processing by means of keyword network analysis}

\author{
Dr Fefie Dotsika \\ Westminster Business School, \\ University of Westminster, \\ London, UK \\ F.E.Dotsika@westminster.ac.uk
}

\begin{abstract}
The purpose of this paper is to identify influential themes and knowledge flows in the area of communications and information processing and suggest trends that are likely to make (or continue making) an impact. We applied keyword network analysis on articles whose keywords match the themes of the International Conference on Communication and Information Processing, collected through the Thompson Reuters' Web of Science and studied the articles' thematic interconnections and their dynamics. The keyword network was found to be clustered around the themes cloud, data, mobile, security, semantic and social. Security and embeddedness are found to be the most dominant topics, common to all groups. Design and performance are key influencers of thematic flows and data mining/analysis are close to all nodes/keywords and therefore most popular. Big data, data fusion/integration and e-government are themes identified as potentially strong future influencers.
\end{abstract}

\section{CCS Concepts}

Information systems $\rightarrow$ Information systems applications $\rightarrow$ Decision support systems $\rightarrow$ Data analytics

Human-centered computing $\rightarrow$ Collaborative and social computing $\rightarrow$ Collaborative and social computing design and evaluation methods $\rightarrow$ Social network analysis

\section{Keywords}

information processing, communication processing, data analysis, network analysis

\section{BACKGROUND}

Looking into journal articles as a complex system where researchers interact with scientific advancements in their subject areas, their environment and with one another, we approach the researchers' scientific output as a complex, dynamic environment of multiple variables and conceptualise it as a network of interconnected themes. The complexity of articles' thematic interconnection increases as the amount of overall publications within a thematic domain multiplies.

\author{
Andrew Watkins \\ Birkbeck \\ University of London, \\ London, UK \\ andrew@dcs.bbk.ac.uk
}

These thematic interconnections uncover technological advancements, flows of information, clusters and hotspots which, when studied, reveal influential developments and trends with significant effects on research, productivity and innovation. The dynamics of themes extend beyond the popularity and currency of subject areas, entering thus into the domain of emergence, trending and forecasting [8], [11].

The current paper focuses on journal publications in the area of communications and information processing. The research interest in the field is widespread as this subject area provides the foundations for sustainable development and has crucial implications in all aspects of life, economy and culture [19], [20]. The publications considered were those matching the themes addressed in the International Conference on Communication and Information Processing. The purpose of the research carried out is to identify clusters, influential themes and knowledge flows in the area, pinpoint current trends and suggest potential future trends that are likely to make an impact.

\section{METHODOLOGY AND RESEARCH DESIGN}

Bibliometric analysis has been used for the detection of technological trends by means of keyword co-occurrence and network analysis [16], [23], [18]. Visualisation techniques have been applied effectively to explore themes, monitor trends and locate interrelated fields [25], [24].

Keyword network analysis, a method best known for its application on social science research [5] has also been successfully employed in bibliometrics with author keywords representing the key points/core concepts of a publication [7], [15]. Network analysis centrality measures have been found efficient in identifying key leading themes in operations management research [3]. Network visualisation techniques and knowledge maps have been effective in theme and emergent trend discovery [14], [15]. Keyword network analysis has been successfully employed in the prediction and forecasting of emergent trends [9], [11]. In addition to these, the method was deemed most appropriate here due to its use of and focus on relational information to investigate and quantify structural properties [22].

Data from academic publications whose keywords match the main themes of the International Conference on Communication and Information Processing were collected through the Thompson Reuters' Web of Science API. The authors' own keywords were then used to create thematic networks by linking co-occurring keywords so that they form linked pairs. As a result, 
the publications within the field covered by the ICCIP conference are represented as a network (graph $\mathrm{G}=(\mathrm{V}, \mathrm{E})$ ) whose nodes $(\mathrm{V})$ correspond to keywords and edges $(\mathrm{E} \subseteq \mathrm{V} \times \mathrm{V})$ to relationships between them. The keywords used in the search can be seen in Table 1.

Table 1. International Conference on Communication and Information Processing Keywords

\begin{tabular}{|l|l|l|}
\hline Access Controls & E-Technology & Real-Time Systems \\
Anti-cyberterrorism & Forensics, & Resource and \\
Assurance of Service & Recognition & Knowledge \\
Biometrics & Technologies and & Discovery Using \\
Technologies & Applications & Social Networks \\
Cloud Computing & Fuzzy and Neural & Self-Organizing \\
Computational & Network Systems & Networks and \\
Intelligence & Green Computing & Networked Systems \\
Computer Crime & Grid Computing & Scalability and \\
Prevention/ Detection & Image Processing & Performance \\
Computer Forensics & Indexing and & Semantic Web, \\
Computer Security & Query Processing & Ontologies \\
Confidentiality & for Moving & Sensor Networks and \\
Protection & Objects & Social Sensing \\
Critical Infrastructure & Information and & Signal Processing, \\
Management & Data Management & Pattern Recognition \\
Data Compression & Information & and Applications \\
Data Management in & Content Security & Social Networks \\
Mobile Peer-to-Peer & Information Ethics & Social Search \\
Networks & Information & Software Engineering \\
Data Mining & Propagation on & Ubiquitous \\
Data Stream & Social Networks & Computing, Services \\
Processing in & Internet Modeling & and Applications \\
Mobile/Sensor & Mobile & User Interfaces and \\
Networks & Networking, & Usability Issues form \\
Distributed and & Mobility and & Mobile Applications \\
Parallel Applications & Nomadicity & User Interfaces, \\
Digital Information & Mobile Social & Visualization and \\
Processing and & Networks & Modeling \\
Communications & Mobile, Ad Hoc & Web Services \\
E-Government & and Sensor & Architecture, \\
E-Learning & Network & Modeling and Design \\
Embedded Systems & Management & Web Services \\
\& Software & Multimedia & Security \\
& Computing & Wireless \\
Network Security & Communications \\
& Peer-to-Peer & XML-Based \\
& Quality of Service & Languages \\
\hline
\end{tabular}

The structure of the created network(s) was explored by means of basic network properties and their metrics and topologies compared to existing models of similar properties. This enabled us to explore thematic relationships and flows. The tools used for the analysis and visualisation were Gephi [2] and UCINET [5].

\section{DATA ANALYSIS}

The (descriptive) basic network metrics calculated and their interpretation can be seen in Table 2. Clustering and sub-network metrics were also calculated to explore the existence of thematic clusters and their integration.

Table 2. Network metrics

\begin{tabular}{|c|c|c|c|}
\hline & Metric & Interpretation & Value \\
\hline \multirow{5}{*}{ 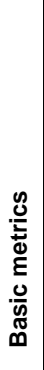 } & Size $n=|V|$ & Thematic richness & 284 \\
\hline & No of links $m=|E|$ & Thematic connectivity & 11079 \\
\hline & $\begin{array}{l}\text { Density } \\
\delta(G)=(2 m / n(n-1 \\
))\end{array}$ & $\begin{array}{l}\text { Ratio of the number of keyword co- } \\
\text { occurrences to the number of all } \\
\text { possible co-occurrences }\end{array}$ & 0.276 \\
\hline & Diameter & $\begin{array}{l}\text { The longest of all the calculated shortest } \\
\text { paths }\end{array}$ & 3 \\
\hline & $\begin{array}{l}\text { Average degree } \\
k=(2 m / n)\end{array}$ & $\begin{array}{l}\text { Degree of a keyword is the number of } \\
\text { edges connected to it }\end{array}$ & 78.021 \\
\hline \multirow{4}{*}{ 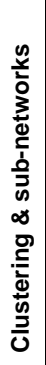 } & $\begin{array}{l}\text { Clustering } \\
\text { coefficient }\end{array}$ & $\begin{array}{l}\text { Ratio of existing links connecting a } \\
\text { node's neighbours to each other to the } \\
\text { maximum possible number of such links }\end{array}$ & 0.488 \\
\hline & $\begin{array}{l}\text { Average } \\
\text { path length }\end{array}$ & $\begin{array}{l}\text { Average number of steps along the } \\
\text { shortest paths for all possible pairs of } \\
\text { keywords }\end{array}$ & 1.727 \\
\hline & Modularity & $\begin{array}{l}\text { Strength of clustering calculated as the } \\
\text { fraction of edges falling within the given } \\
\text { groups minus the expected such fraction } \\
\text { if edges were randomly distributed }\end{array}$ & 0.395 \\
\hline & Communities & Thematic clusters & 6 \\
\hline
\end{tabular}

The modularity of the network is relatively high (modularity values range from -1 to 1 ) which suggests that there is a high strength of clustering. The short average path length and high clustering co-efficient metrics suggest that the network is of the small-world type characterised by short average path length and high clustering coefficient. Therefore the network contains interconnected thematic communities, each of which is internally strongly connected.

Based on this we used the Louvain method [4] for direct community detection and the network was found indeed to have a "community structure", that is, a clear distinction between sets of nodes densely connected to each-other and less well connected to the rest of the network. Six clear communities were identified, whose locality and main themes are depicted in Figure 1 .

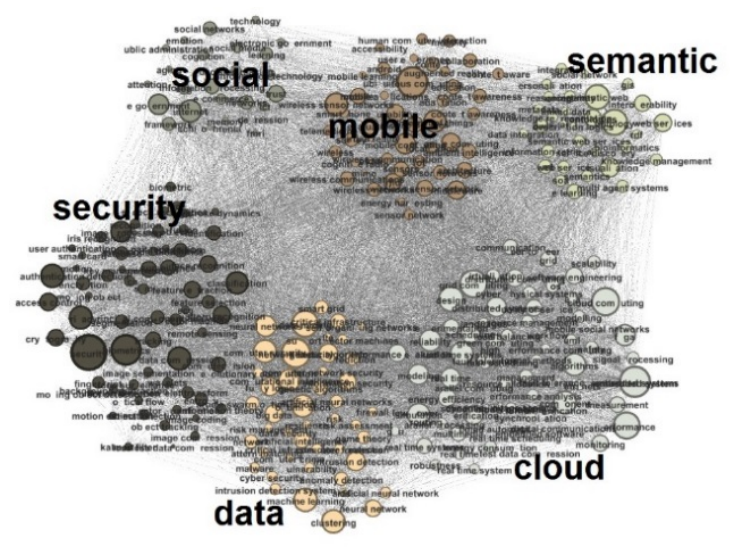

\begin{tabular}{|l|c|}
\hline cloud & $25.7 \%$ \\
\hline data & $15.85 \%$ \\
\hline mobile & $16.2 \%$ \\
\hline security & $22.54 \%$ \\
\hline semantic & $10.92 \%$ \\
\hline social & $8.8 \%$ \\
\hline
\end{tabular}

Figure 1. Thematic communities 


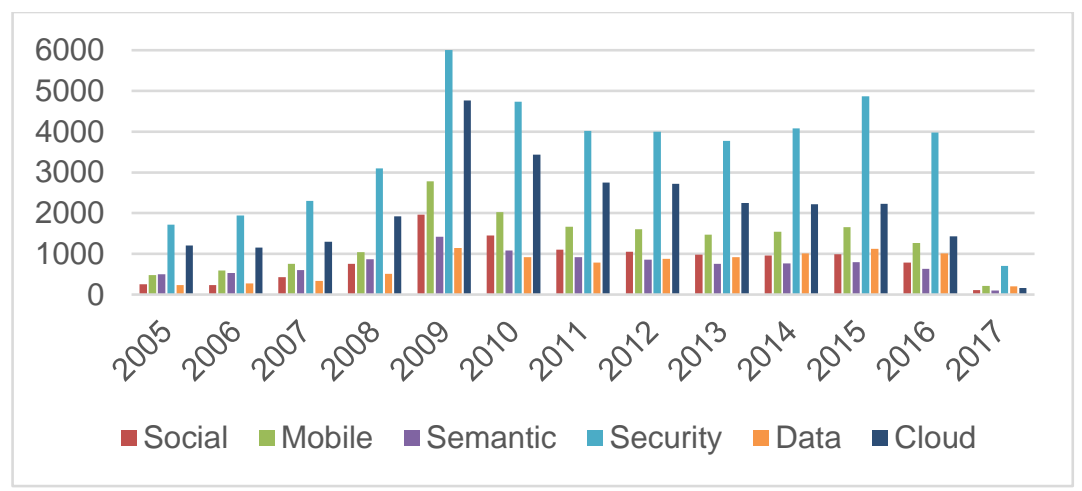

Figure 2. Thematic distribution of publications

The thematic communities revolve around six clearly defined themes: social (including social web, e-*, social media/networks, etc.), semantic (incl. semantic technologies, semantic web, ontologies, XML-based languages, etc.), data (incl. big data, data analytics, data mining, fuzzy/neural networks, etc.), mobile (incl. ubiquitous computing, P2P, mobile net. management, etc.), security (incl. cryptography/encryption, cyberterrorism, computer forensics, etc.), and cloud (incl. cloud computing, web services, grid computing, scalability etc.). The thematic distribution of number of publications (axis y) by year (2005-2017) can be seen in Figure 2.

Centrality metrics were calculated to aid the positional analysis of the network, identifying the keywords/themes that occupy distinguished positions among the nodes [22]. These were degree, closeness and betweeness centralities. Table 3 presents the metrics, their interpretation and the highest/lowest scoring keywords in each category.

Table 3. Centrality metrics

\begin{tabular}{|c|c|c|c|}
\hline Metric & Interpretation & $\begin{array}{l}\text { High scoring } \\
\text { keywords }\end{array}$ & $\begin{array}{l}\text { Low scoring } \\
\text { keywords }\end{array}$ \\
\hline $\begin{array}{l}\text { Degree centrality } \\
\text { (node i) } \\
C_{D}(i)=\sum_{j=1}^{n} x_{i j} \\
\text { where } x_{i j} \text { is a tie from } \\
\text { node } i \text { to node } j\end{array}$ & $\begin{array}{l}\text { Number of links } \\
\text { of a keyword. }\end{array}$ & $\begin{array}{l}\text { security } \\
\text { embedded } \\
\text { systems } \\
\text { semantic web } \\
\text { cloud }\end{array}$ & $\begin{array}{l}\text { data compression } \\
\text { timed automata } \\
\text { mimo (multiple i/o) } \\
\text { schedulability }\end{array}$ \\
\hline $\begin{array}{l}\text { Betweenness } \\
\text { centrality } \\
C_{B}(i)=\sum g_{j k}(i) / \\
g_{j k}, i \neq j \neq k \text { where } \\
g_{j k} \text { the no of shortest } \\
\text { paths connecting } j \\
\text { and } \\
k \text { and } g_{j k}(i) \text { the no of } \\
\text { shortest paths } \\
\text { between } j \text { and } k \text { that } \\
\text { pass through } i \text {. }\end{array}$ & $\begin{array}{l}\text { The number of } \\
\text { times a keyword } \\
\text { acts as a link } \\
\text { along the } \\
\text { shortest path } \\
\text { between two } \\
\text { other keywords. }\end{array}$ & $\begin{array}{l}\text { security } \\
\text { embedded } \\
\text { systems } \\
\text { performance } \\
\text { design }\end{array}$ & $\begin{array}{l}\text { data compression } \\
\text { timed automata } \\
\text { mobile learning } \\
\text { description logistics }\end{array}$ \\
\hline $\begin{array}{l}\text { Closeness centrality } \\
C_{c}(i)=\sum_{j=1}^{n} d_{i j} \\
\text { where } d_{i j} \text { is the } \\
\text { distance connecting } \\
\text { nodes } i \text { and } j .\end{array}$ & $\begin{array}{l}\text { A keyword's } \\
\text { distance to all } \\
\text { other keywords. }\end{array}$ & $\begin{array}{l}\text { security } \\
\text { embedded } \\
\text { systems } \\
\text { data mining } \\
\text { grid computing }\end{array}$ & $\begin{array}{l}\text { data compression } \\
\text { fmri (functional mri) } \\
\text { description logistics } \\
\text { moving object } \\
\text { detection }\end{array}$ \\
\hline
\end{tabular}

Degree centrality is interpreted as a node's (keyword's) popularity and influence of its position in linking trends and controlling thematic flows. Closeness centrality is interpreted as the degree to which a keyword/theme is near all other keywords in the network. Betweeness is interpreted as a measurement of influence in the flow of information in the network. In order to further analyse the centrality metrics we use visualisation based on the ranking of the keywords for degree, betweeness and closeness centralities. In the graphic representations, nodes' sizes are depicted ranked according to their centrality scores: the higher the centrality, the larger the node. The results can be seen in Figure 3 (left to right: degree, betweeness and closeness).

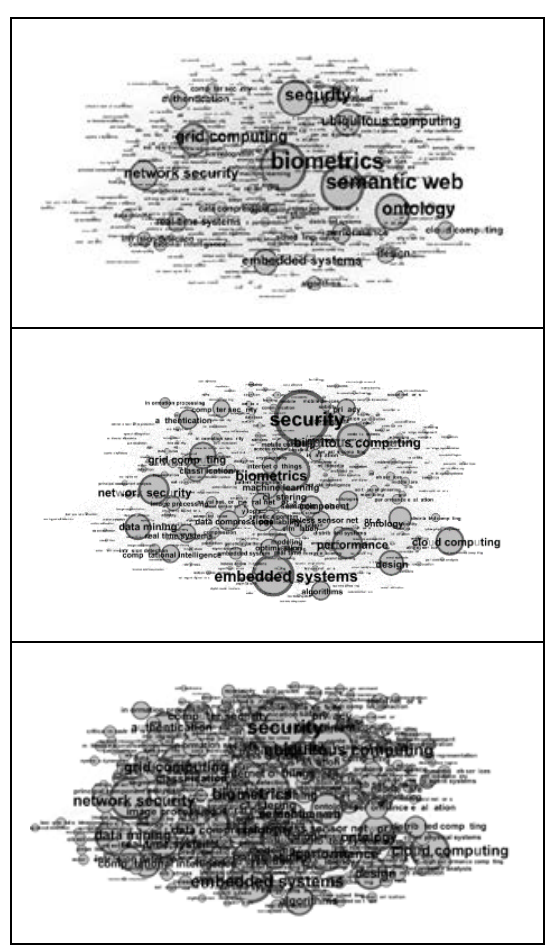

Figure 3. Degree, betweeness and closeness centralities

The degree centrality used here is weighted (weight of each edge has been taken into account). From the three graphs the closeness centrality is the most difficult to read, as the nodes overlap significantly. Instead of "spreading" the graph to avoid overlapping, we kept the format to enable cross-centrality comparisons. Security and embeddedness are prominent in all graphs as expected. They represent well-established strongholds 
of thematic flows. From the first graph (degree centrality) we identify biometrics, semantic web and ontology as the most prominent/popular themes. In the second graph (betweeness) security, biometrics and embedded systems appear as the most influential themes. As expected, less connected themes of low centralities such as data compression and description logistics (identified as such in Table 3) are barely visible here. They signify topics of little influence within the group, or niche interest.

There is a special category of keywords that are identified through centrality measures that are in conflict with one another [17]. These keywords have at least one high centrality metric and one low. In our dataset, topics such as semantic web and ontologies are popular (i.e. have high degree centrality) but do not act as links of thematic domains (i.e. have low betweeness centrality). On the other hand, machine learning and image processing are influential (high betweeness) but not necessarily popular (low degree). From this special category, keywords with high closeness and low degree are central, noteworthy trends that have been recognised as either likely to keep trending, or having potentially significant future impact [11]. Big data, data fusion/integration and e-government have been identified as such themes here.

\section{DISCUSSION AND CONCLUSIONS}

Keyword network analysis has been used here to analyse knowledge flows and influential themes in a network of keywords from published articles matching the topics of the International Conference on Communication and Information Processing. The total of 75047 articles were collected through the Thompson Reuters' Web of Science API (publications are included as appearing at the end of June 2017). The network was created by linking co-occurring authors' keywords (a total of 281914).

The paper's implication for research is that the method was found suitable for theme analysis and for the identification of strong current and potential future trends in accordance with similar research [26]. Visualisation was possible due to the relatively small size of the network, a fact that further facilitated the study and analysis of data. Clear and distinct clusters were identified around six major themes: cloud, data, mobile, security, semantic and social. The topics of security and embeddedness were found to be the most dominant themes and were common to all groups. Thematic flows were found to be significantly influenced by the keywords design and performance. These results reflect and reinforce current research and are in line with top ranked market reports.

The topics identified as strong future influences were related to big data, data fusion and data integration. As before, our results reflect and are supported by recent academic research [6], [9] and industrial publications [13], [12]. E-government (and associated themes such as e-government pathways, service innovation and smart cities) was another theme that scored high as a future research trend and influencer. Research in the area follows critical developments in information processing and communication and is expected to generate significant research and innovation [21], [1].

Communication and information processing are, and will continue to be, heavily influenced by the themes of big data, data fusion/integration, and e-government. This has implications for practice as it creates new opportunities for timely research in these areas and identifies themes that ought to be considered, reflected and perhaps highlighted in the focus of future conferences in the field.
The results are indicative and require further research to confirm the nature of the identified trends. A potential study would be to carry out a longitudinal analysis that would help compare earlier trend identification. This is the area of future research.

\section{REFERENCES}

[1] Barrett, M., Davidson, E., Prabhu, J., \& Vargo, S. L. (2015). Service innovation in the digital age: key contributions and future directions. MIS quarterly, 39(1), 135-154.

[2] Bastian M., Heymann S., Jacomy M. (2009). Gephi: an open source software for exploring and manipulating networks. International AAAI Conference on Weblogs and Social Media.

[3] Behara, S., Babbar, R. S., \& Andrew Smart, P. (2014). Leadership in OM research: a social network analysis of European researchers. International Journal of Operations \& Production Management, 34(12), 1537-1563.

[4] Blondel, V. D., Guillaume, J. L., Lambiotte, R., \& Lefebvre, E. (2008). Fast unfolding of communities in large networks. Journal of Statistical Mechanics: Theory and Experiment, 2008(10), P10008.

[5] Borgatti, S.P., Everett, M.G. and Freeman, L.C. (2002), Ucinet for Windows: Software for Social Network Analysis. Harvard, MA: Analytic Technologies

[6] Chen, M., Mao, S., \& Liu, Y. (2014). Big data: A survey. Mobile Networks and Applications, 19(2), 171-209.

[7] Chiu, W. T., \& Ho, Y. (2007). Bibliometric analysis of tsunami research. Scientometrics, 73(1), 3-17.

[8] Choi, J., \& Hwang, Y. S. (2014). Patent keyword network analysis for improving technology development efficiency. Technological Forecasting and Social Change, 83, 170-182.

[9] Choi, J., Yi, S., \& Lee, K. C. (2011b). Analysis of keyword networks in MIS research and implications for predicting knowledge evolution. Information \& Management, 48(8), 371-381.

[10] Dong, X. L., \& Srivastava, D. (2015). Big data integration. Synthesis Lectures on Data Management, 7(1), 1-198.

[11] Dotsika, F. and Watkins, A. (2017) Identifying potentially disruptive trends by means of keyword network analysis. Technological Forecasting \& Social Change, 119. pp. 114127. ISSN 0040-1625

[12] Forbes, (2016), 2017 predictions, online, https://www.forbes.com/sites/gilpress/2016/12/12/2017predictions-for-ai-big-data-iot-cybersecurity-and-jobsfrom-senior-tech-executives/\#1c4c8e077a73, online, accessed July 22017

[13] Gartner, (2016), Gartner Survey Reveals Investment in Big Data Is Up, online, http://www.gartner.com/newsroom/id/3466117, accessed July 22017

[14] Kim, Y. G., Suh, J. H., \& Park, S. C. (2008). Visualization of patent analysis for emerging technology. Expert Systems with Applications, 34(3), 1804-1812.

[15] Lee, P. C., \& Su, H. N. (2010). Investigating the structure of regional innovation system research through keyword cooccurrence and social network analysis. Innovation, 12(1), 26-40. 
[16] Li, H., An, H., Wang, Y., Huang, J., \& Gao, X. (2016). Evolutionary features of academic articles co-keyword network and keywords co-occurrence network: Based on two-mode affiliation network. Physica A: Statistical Mechanics and its Applications, 450, 657-669.

[17] Liang, Y., Chen, J., 2011. Group network centrality analysis of blogs in politics. Commun. Inform. Sci. Manag. Eng.

[18] Park, H., Kim, K., Choi, S., \& Yoon, J. (2013). A patent intelligence system for strategic technology planning. Expert Systems with Applications, 40(7), 2373-2390.

[19] Roy, S., Ahmed, A. M. M., \& Abonamah, A. A. (2014). ICT and Economic Growth: Evidence from Twelve MENA Economies. International Journal of Customer Relationship Marketing and Management (IJCRMM), 5(1), 16-30.

[20] Schank, R. C. (2014). Conceptual information processing (Vol. 3). Elsevier.

[21] Snead, J. T., \& Wright, E. (2014). E-government research in the United States. Government Information Quarterly, 31(1), 129-136.
[22] Wasserman, S., \& Faust, K. (1994). Social network analysis: Methods and applications (Vol. 8). Cambridge university press.

[23] Wu, C. C. (2016). Constructing a weighted keyword-based patent network approach to identify technological trends and evolution in a field of green energy: a case of biofuels. Quality \& Quantity, 50(1), 213-235.

[24] Yang, S., Han, R., Wolfram, D., \& Zhao, Y. (2016). Visualizing the intellectual structure of information science (2006-2015): Introducing author keyword coupling analysis. Journal of Informetrics, 10(1), 132-150.

[25] Yoon, B., Lee, S., \& Lee, G. (2010). Development and application of a keyword-based knowledge map for effective R\&D planning. Scientometrics, 85(3), 803-820.

[26] Yoon, B., \& Park, Y. (2004). A text-mining-based patent network: Analytical tool for high-technology trend. The Journal of High Technology Management Research, 15(1), 37-50. 